\title{
Spraying Method of Administration
}

National Cancer Institute

\section{Source}

National Cancer Institute. Spraying Method of Administration. NCI Thesaurus. Code C149950.

The technique of administration of a pharmaceutical product by atomizing or otherwise dissipating it into a fine dispersion of particles in air, directing it such that it comes into contact with the affected area. 